This PDF is a selection from an out-of-print volume from the National Bureau of Economic Research

Volume Title: New Developments in Productivity Analysis

Volume Author/Editor: Charles R. Hulten, Edwin R. Dean and Michael J. Harper, editors

Volume Publisher: University of Chicago Press

Volume ISBN: 0-226-36062-8

Volume URL: http://www.nber.org/books/hult01-1

Publication Date: January 2001

Chapter Title: Which (Old) Ideas on Productivity Measurement Are Ready to Use?

Chapter Author: W. Erwin Diewert

Chapter URL: http://www.nber.org/chapters/c10124

Chapter pages in book: (p. 85 - 102) 


\title{
Which (Old) Ideas on Productivity Measurement Are Ready to Use?
}

\author{
W. Erwin Diewert
}

\subsection{Introduction}

The organizers of this conference gave me two tasks: (1) to review the paper on the BLS productivity measurement program by Dean and Harper (ch. 2, this volume), and (2) to suggest which new ideas on productivity measurement are ready to be embraced by statistical agencies and implemented in the near future.

I was able to complete the first task with admirable efficiency: I could find absolutely nothing to criticize in the Dean and Harper paper. They describe the history of the BLS labor and multifactor productivity (MFP) programs and indicate where the work is going in the future in an accurate and entertaining fashion. Of course, the BLS has been the world leader among statistical agencies in developing MFP measures and in incorporating new theoretical developments as they become available.

I was not able to complete the second task so efficiently. I could not think of any new ideas on productivity measurement that were ready to be implemented, but I was able to think of many old ideas that perhaps are. Thus, the remainder of this chapter concentrates on my second task (with the word new replaced by the word old).

Before I jump into the content of this chapter, perhaps it would be useful to remind people of the definition of productivity. Productivity is the output of a production unit (establishment, firm, industry, economy) divided by the input used over a given time period. Productivity growth of a production unit is the rate of growth of its output divided by the rate of growth 
of its input used over two time periods. Partial productivity measures are obtained by including only a subset of all of the outputs produced and inputs utilized by the production unit. For example, labor productivity is output (or value added) divided by labor input, and is a partial productivity measure because it neglects the contributions of other inputs, such as capital and land. On the other hand, MFP (or total factor productivity) includes all outputs produced and inputs utilized by the production unit.

Although labor productivity does have its uses, MFP seems to me to be the more useful measure of productivity. A rapid growth in a partial productivity measure could be due to a rapid growth in an omitted input category and thus could be quite misleading. In the remainder of this chapter, I will concentrate on some of the difficulties involved in measuring MFP.

It turns out that many classes of outputs and inputs are still not being measured adequately by statistical agencies. Thus, the old main idea that I would like to suggest to statistical agencies is that more effort should be put into measuring the major classes of inputs and outputs that production units produce and use. In sections 3.2-3.8, I review the main classes of outputs and inputs that statistical agencies must measure in order to form accurate measures of MFP for production units, and I discuss some of the measurement difficulties associated with each class. In sections 3.93.11 , more esoteric capital inputs are discussed. It would be desirable to measure these inputs as well, but perhaps the appropriate methodology is not yet available.

Section 3.12 comments on the "optimal" organization of a statistical system that would measure MFP with more accuracy. Section 3.13 looks at the difference between the efficiency of particular production units and the efficiency of the economy as a whole. Section 3.14 concludes with some observations on the difficulties facing statistical agencies in this time of rapid change.

\subsection{Gross Outputs}

In order to measure the productivity of a firm, industry, or economy, one needs information on the outputs produced by the production unit for each time period in the sample, along with the average price received by the production unit in each period for each of the outputs. In practice, period-by-period information on revenues received by the industry for a list of output categories is required along with either an output index or a price index for each output. In principle, the revenues received should not include any commodity taxes imposed on the industry's outputs, because producers in the industry do not receive these tax revenues. The preceding sentences sound very straightforward, but many firms produce thousands 
of commodities, so the aggregation difficulties are formidable. Moreover, many outputs in service-sector industries are difficult to measure conceptually: Think of the proliferation of telephone service plans and the difficulties involved in measuring insurance, gambling, banking, and options trading.

\subsection{Intermediate Inputs}

Again, in principle, one requires information on all the intermediate inputs utilized by the production unit for each time period in the sample, along with the average price paid for each of the inputs. In practice, period-by-period information on costs paid by the industry for a list of intermediate input categories is required, along with either an intermediate input quantity index or a price index for each category. In principle, the intermediate input costs paid should include any commodity taxes imposed on the intermediate inputs because these tax costs are actually paid by producers in the industry.

The major classes of intermediate inputs at the industry level are materials, business services, and leased capital.

The current input-output framework deals reasonably well in theory with the flows of materials but not with intersectoral flows of contracted labor services or rented capital equipment. The input-output system was designed long ago, when the leasing of capital was uncommon and when firms had their own in-house business services providers. Thus there is little or no provision for business service and leased capital intermediate inputs in the present system of accounts. With the exception of the manufacturing sector, even the intersectoral value flows of materials are largely incomplete in the industry statistics.

This lack of information means the current input-output accounts will have to be greatly expanded to construct reliable estimates of real value added by industry. At present, there are no surveys (to my knowledge) on the interindustry flows of business services or on the interindustry flows of leased capital. Another problem is that using present national accounts conventions, leased capital resides in the sector of ownership, which is generally the finance sector. This leads to a large overstatement of the capital input into finance and a corresponding underestimate of capital services into the sectors actually using the leased capital.

It should be noted that at the level of the entire market economy, intermediate inputs collapse down to only imports plus purchases of government and other nonmarket inputs. This simplification of the hugely complex web of interindustry transactions of goods and services explains why it may be easier to measure productivity at the national level than at the industry level. 


\subsection{Labor Inputs}

Using the number of employees as a measure of labor input into an industry will not usually be a very accurate measure of labor input, due to the long-term decline in average hours worked per full-time worker and the recent increase in the use of part-time workers. However, even total hours worked in an industry is not a satisfactory measure of labor input if the industry employs a mix of skilled and unskilled workers. Hours of work contributed by highly skilled workers generally contribute more to production than do hours contributed by very unskilled workers. Hence, it is best to decompose aggregate labor compensation into its aggregate price and quantity components using index number theory. The practical problem faced by statistical agencies is: How should the various categories of labor be defined? Alternative approaches to this problem are outlined in Jorgenson and Griliches (1967), BLS (1983), Denison (1985), Jorgenson, Gollop, and Fraumeni (1987), and Jorgenson and Fraumeni (1989, 1992). Dean and Harper (ch. 2, this vol.) provide an accessible summary of the literature in this area.

Another important problem associated with measuring real labor input is finding an appropriate allocation of the operating surplus of proprietors and the self-employed into labor and capital components. There are two broad approaches to this problem. In the first, if demographic information on the self-employed is available along with hours worked, then an imputed wage can be assigned to those hours worked based on the average wage earned by employees of similar skills and training. Then an imputed wage bill can be constructed and subtracted from the operating surplus of the self-employed, and the reduced amount of operating surplus can be assigned to capital. In the second approach, if information on the capital stocks utilized by the self-employed is available, then these capital stocks can be assigned user costs and an aggregate imputed rental can be subtracted from operating surplus; the reduced amount of operating surplus can then be assigned to labor. These imputed labor earnings can then be divided by hours worked by proprietors to obtain an imputed wage rate.

The problems posed by allocating the operating surplus of the selfemployed are becoming increasingly more important as this type of employment grows. As far as we can determine, little has been done in countries other than the United States to resolve these problems. Fundamentally, the problem appears to be that the current System of National Accounts (SNA) does not address this problem adequately.

\subsection{Reproducible Capital Inputs}

When a firm purchases a durable capital input, it is not appropriate to allocate the entire purchase price as a cost to the initial period when the 
asset was purchased. It is necessary to distribute this initial purchase cost across the useful life of the asset. National income accountants recognize this and use depreciation accounts to do the distribution of the initial cost over the life of the asset. However, national income accountants are reluctant to recognize the interest tied up in the purchase of the asset as a true economic cost. Rather, they tend to regard interest as a transfer payment. Thus the user cost of an asset (which recognizes the opportunity cost of capital as a valid economic cost) is not regarded by many national income accountants as a valid approach to valuing the services provided by a durable capital input. However, if a firm buys a durable capital input and leases or rents it to another sector, national income accountants regard the induced rental as a legitimate cost for the using industry. It seems very unlikely that the leasing price does not include an allowance for the capital tied up by the initial purchase of the asset; that is, market rental prices include interest. Hence, it seems reasonable to include an imputed interest cost in the user cost of capital even when the asset is not leased. Put another way, interest is still not accepted as a cost of production in the SNA, since it is regarded as an unproductive transfer payment. However, interest is productive; it is the cost of inducing savers to forego immediate consumption.

The treatment of capital gains on assets is even more controversial than the national accounts treatment of interest. In the national accounts, capital gains are not accepted as an intertemporal benefit of production, but if resources are transferred from a period in which they are less valuable to one in which they are more highly valued, then a gain has occurred; that is, capital gains are productive according to this view.

However, the treatment of interest and capital gains poses practical problems for statistical agencies. For example, which of the following interest rates should be used?

1. An ex post economy-wide rate of return, which is the alternative used by Christensen and Jorgenson $(1969,1970)$.

2. An ex post firm or sectoral rate of return. (This method seems appropriate from the viewpoint of measuring ex post performance.)

3. An ex ante safe rate of return, such as a Federal Government oneyear bond rate. (This method seems appropriate from the viewpoint of constructing ex ante user costs that could be used in econometric models.)

4. An ex ante safe rate, adjusted for the risk of the firm or industry.

Because the ex ante user-cost concept is not observable, the statistical agency will have to make somewhat arbitrary decisions in order to construct expected capital gains. This is a strong disadvantage of the ex ante concept. On the other hand, the use of the ex post concept will lead to rather large fluctuations in user costs, which in some cases will lead to negative user costs, which in turn may be hard to explain to users. How- 
ever, a negative user cost simply indicates that instead of the asset's declining in value over the period of use, it rose in value to a sufficient extent to offset deterioration. Hence, instead of the asset's being an input cost to the economy during the period, it becomes an intertemporal output. For further discussion of the problems involved in constructing user costs, see Diewert (1980, 470-86). For evidence that the choice of user cost formula matters, see Harper, Berndt, and Wood (1989).

The distinction between depreciation (a decline in value of the asset over the accounting period) and deterioration (a decline in the physical efficiency of the asset over the accounting period) is now well understood but still has received little recognition in the latest version of the SNA.

A further complication is that our empirical information on the actual efficiency decline of assets is weak. We do not have good information on the useful lives of assets. The U.K. statistician assumes that machinery and equipment in manufacturing last twenty-six years on average, while the Japanese statistician assumes machinery and equipment in manufacturing last eleven years on average, see $\operatorname{OECD}(1993,13)$. The problems involved in measuring capital input are also being addressed by the Canberra Group on Capital Measurement, which is an informal working group of international statisticians dedicated to resolving some of these measurement problems.

A final set of problems associated with the construction of user costs is the treatment of business income taxes: Should we assume that firms are as clever as Hall and Jorgenson (1967) and can work out their rather complex tax-adjusted user costs of capital, or should we go to the accounting literature and allocate capital taxes in the rather unsophisticated ways that are suggested there?

\subsection{Inventories}

Because interest is not a cost of production in the national accounts and the depreciation rate for inventories is close to zero, most productivity studies neglect the user cost of inventories. This leads to misleading productivity statistics for industries such as retailing and wholesaling, in which inventories are large relative to output. In particular, rates of return that are computed neglecting inventories will be too high because the opportunity cost of capital that is tied up in holding the beginning of the period stocks of inventories is neglected.

The problems involved in accounting for inventories are complicated by the way that accountants and tax authorities treat inventories. These accounting treatments of inventories are problematic in periods of high or moderate inflation. A treatment of inventories that is suitable for productivity measurement can be found in Diewert and Smith (1994). These inventory accounting problems seem to carry over to the national accounts 
in that, for virtually all OECD countries, there are time periods in which the real change in inventories has the opposite sign to the corresponding nominal change in inventories. This seems logically inconsistent.

\subsection{Land}

The current SNA has no role for land as a factor of production, perhaps because it is thought that the quantity of land in use remains roughly constant across time and hence can be treated as a fixed, unchanging factor in the analysis of production. However, the quantity of land in use by any particular firm or industry does change over time. Moreover, the price of land can change dramatically, so that the user cost of land will also change over time; this changing user cost will, in general, affect correctly measured productivity.

Land ties up capital just as inventories do (both are zero-depreciation assets). Hence, when computing ex post rates of return earned by a production unit, it is important to account for the opportunity cost of capital tied up in land. Neglect of this factor can lead to biased rates of return on financial capital employed. Thus, industry rates of return and total factor productivity (TFP) estimates may not be accurate for sectors such as agriculture that are land intensive.

Finally, property taxes that fall on land must be included as part of the user cost of land. In general, it may not be easy to separate the land part of property taxes from the structures part. In the national accounts, property taxes (which are input taxes) are lumped together with other indirect taxes that fall on outputs, which is another shortcoming of the current SNA.

\subsection{Resources}

Examples of resource inputs include depletion of fishing stocks, forests, mines and oil wells; and improvement of air, land, or water environmental quality (these are resource "outputs" if improvements have taken place and are resource "inputs" if degradation has occurred).

The correct prices for resource depletion inputs are the gross rents (including resource taxes) that these factors of production earn. Resource rents usually are not linked up with the depletion of resource stocks in the national accounts, although some countries (including the United States and Canada), are developing statistics for forest, mining, and oil depletion; see Nordhaus and Kokkelenberg (1999).

The pricing of environmental inputs or outputs is much more difficult. From the viewpoint of traditional productivity analysis based on shifts in the production function, the "correct" environmental quality prices are marginal rates of transformation while, from a consumer welfare point of 
view, the "correct" prices are marginal rates of substitution; see Gollop and Swinand (ch. 14, this volume).

The environmental situation is somewhat analogous to the case of a government enterprise that is told to provide services at prices well below marginal cost. In this case, it is useful to have an addendum to the accounts that revalues the subsidized goods and services at market (i.e., consumer) prices; this treatment would also be useful in the case of environmental goods and services. The problem with this suggestion is that it is much more difficult to estimate the appropriate consumer or producer environmental prices than it is to estimate the market price of a state subsidised good such as housing. Some techniques that could perhaps be used to estimate appropriate environmental prices and quantities are engineering studies (for the determination of producer environmental prices); epidemiological studies (for the determination of consumer environmental prices); and econometric and statistical techniques (which may also be useful in determining these producer and consumer environmental prices).

It is likely that environmental prices constructed using the previous techniques would not satisfy a reproducibility test - that is, different resource economists and statisticians would not come up with the same prices. This means that statistical agencies will have to be cautious in providing environmental accounts.

The above seven major classes of inputs and outputs discussed in sections 3.2-3.8 represent a minimal classification scheme for organizing information to measure TFP at the sectoral level. Unfortunately, no country has yet been able to provide satisfactory price and quantity information on all seven of these classes. To fill in the data gaps, it would be necessary for governments to expand the budget of the relevant statistical agencies considerably. This is one area of government expenditure that cannot be readily filled by the private sector. Given the importance of productivity improvements in improving standards of living, the accurate measurement of productivity seems necessary.

There are also additional types of capital that should be distinguished in a more complete classification of commodity flows and stocks, such as knowledge or intellectual capital, working capital or financial capital, infrastructure capital, and entertainment or artistic capital. Knowledge capital, in particular, is important for understanding precisely how process and product innovations (which drive TFP) are generated and diffused. In the following sections, I will comment on some of the measurement problems associated with these more esoteric kinds of capital.

\subsection{Knowledge Capital}

It is difficult to define what is meant by knowledge capital and innovation. I attempt to define these concepts in the context of production theory.

We think in terms of a local market area. In this area, there is a list of 
establishments or production units. Each establishment produces outputs and uses inputs during each period that it exists. Establishment knowledge at a given time is the set of input and output combinations that a local establishment could produce during at that given time period $t$. It is the economist's period $t$ production function or period $t$ production possibilities set. Establishment innovation is the set of new input-output combinations that an establishment in the local market area could produce in the current period compared to the previous period; that is, it is the growth in establishment knowledge or the increase in the size of the current period production possibilities set compared to the previous period's set. Since the statistical agency cannot know exactly what a given establishment's production possibilities are at any moment in time, it will be difficult to distinguish between the substitution of one input for another within a given production possibilities set versus an expansion of the production possibilities set; that is, it will be difficult to distinguish between substitution along a production function versus a shift in the production function.

Note that both process and product innovations are included in this definition of establishment innovation. Product innovations lead to additions to the list of outputs; traditional index number theory is not well adapted to deal with these additions, but the shadow price technique introduced by Hicks $(1940)^{1}$ and implemented by Hausman $(1997,1999)$ could be used.

Note also that this definition of establishment innovation includes all technology transfers from outside the establishment. One could further decompose innovations into local ones or global ones. A global innovation is the invention of a new set of input-output coefficients for the first time in the world; that is, the invention of a brand new product, process, or method of organization. A local innovation to a given establishment is merely the application of a global innovation to the local marketplace. However, local innovations are just as important as global innovations. A global innovation developed somewhere else in the world is useless to a local business unit if the new technology is not transmitted or diffused to the local establishment. In my view, the diffusion of a new product or process to the local economy is at least as important as the actual creation of the new knowledge for the first time. ${ }^{2}$

1. Hicks $(1969,55-56)$ later described these index number difficulties as follows: "Gains and losses that result from price changes (such as those just considered) would be measurable easily enough by our regular index number technique, if we had the facts; but the gains which result from the availability of new commodities, which were previously not available at all, would be inclined to slip through. (This is the same kind of trouble as besets the modern national income statistician when he seeks to allow for quality changes.) ... The variety of goods available is increased, with all the widening of life that that entails. This is a gain which quantitative economic history which works with index numbers of real income, is illfitted to measure or even describe."

2. This highlights the important role that business consulting firms can play in diffusing best-practice technology or organizational techniques into the local economy. 
How can we measure knowledge capital? Given the definition of knowledge as time-dependent, firm-specific production possibilities sets, it is extremely difficult to measure knowledge and changes in it (innovation). Some of the possible input-output combinations that a production unit can produce are imbedded in its capital equipment and the accompanying manuals. Other possible combinations of inputs and outputs might be imbedded in its patents or the unpublished notes of the scientists that developed the patents; yet other combinations might be imbedded in the brains of its workers. However, certain stocks can be measured that will probably be positively correlated with the size of local knowledge stocks. A science and technology statistical system should concentrate on collecting information on these knowledge related stocks. Some possible candidates for data collection are

1. stocks of patents (How should these be valued, and what depreciation rate should be used?)

2. research and development expenditures (How should these be deflated and what depreciation rate should be used?)

3. education and training undertaken in the firm (How should this be valued?)

4. trade fairs and professional meetings (In the local area only, or should the fairs and meetings abroad attended by local employees also be counted?)

5. availability of universities and research labs in the local region

6. stocks of books, journals, blueprints within the firm

7. availability of local libraries

8. local availability of trade magazines, newspapers, and how-to books (i.e., availability of local bookstores)

9. availability of mail service

10. availability of Internet services

11. ease of access to business consultants who can tell firms what bestpractice input-output coefficients look like, then help the business unit to achieve the best-practice technology

12. participation of the local community in business associations, clubs, and societies

Obviously, it is very difficult to pin down exactly how knowledge flows into the local economy. Government regulations can also cause valuable knowledge flows. For example, my local building code now specifies that a layer of plastic insulation must be placed below ground-level concrete floors when the building is being constructed. This is relatively inexpensive but is very valuable in preventing loss of heat through the floor. Also, local building contractors must be licensed. Firms that sell new technologies obtain mailing lists of contractors from the licensing authority, and the contractors then receive useful information on new products. 
These considerations bring up the positive role of advertising and marketing in transmitting useful information about new products and technologies to other business units.

\subsection{Infrastructure Capital}

Examples of infrastructure capital inputs are roads, airports, harbors, water supply, electricity supply, sewage disposal, garbage disposal, and telephone, cable television, and Internet hookups. Many of these stocks will appear in the list of reproducible capital stocks if privately owned. However, it still may be useful to distinguish the various types of infrastructure capital from ordinary structures. Publicly owned roads present special problems: They provide valuable services to business users but their price to the users is zero. Here is another example of demand prices' being quite different from supply prices.

There is a connection of infrastructure capital with knowledge capital. From Adam Smith and Alfred Marshall, we know that the bigger the market, the more establishments can specialize (i.e., create new local commodities). Thus reduction of transportation costs within and outside the local region can widen the market and reduce the costs of importing knowledge.

Similarly, a reduction in communication costs can make international and interregional knowledge more accessible to local establishments. Thus it seems likely that regions that are "large" and have "good" infrastructure facilities will have easier access to knowledge stocks, which, in turn, should lead to higher rates of productivity growth.

\subsection{Entertainment or Artistic Capital}

Examples of this type of capital include movies, paintings, novels, and games. Hill (1999) deals with this type of artistic, literary, or cultural capital. As was the case with the previous three types of capital, the cost of producing a piece of entertainment capital can be quite unrelated to its eventual value as a consumer service. Again, we have difficult practical valuation problems (how much money will the movie Titanic eventually make?) and difficult conceptual valuation problems (how can we justify a consumer valuation of the movie when, for productivity purposes, we are supposed to use a cost-of-production valuation?).

Before moving on to other productivity related topics, I sum up the previous material on measuring inputs and outputs of a production unit. Note that most productivity studies use only the information associated with output category 1 (outputs) and input categories 2 (intermediate inputs), 3 (labor), and 4 (reproducible capital). Typically, labor productivity studies use information from only categories 1 and 3, while many TFP 
studies use information from only categories 1,3 , and 4 . I believe that these productivity studies are of very limited use. A more meaningful productivity study would use information on all categories and use at least categories 1-6; however, the valuation problems in categories 7-10 are formidable, both from the practical and conceptual points of view.

\subsection{Productivity and the Organization of the Statistical System}

In this section, we comment on the difficulties that statistical agencies may have in piecing together information from very different sources in order to construct multifactor or total factor productivity estimates.

The basic problem is this: Every statistical agency uses different surveys to collect information on the outputs of an industry and on the various input components. Furthermore, every statistical agency uses different surveys to collect information on prices and values.

These separate data-collection surveys do not greatly impede the construction of reasonably accurate price and quantity aggregates for the components of final demand for the economy as a whole, but they do lead to extremely inaccurate estimates of prices and quantities for industries or smaller units such as firms or establishments. In particular, the firm- or industry-specific price indexes that are applied to the firm's or industry's value components (such as output, intermediate input, labor input, etc.) will typically be very inaccurate. Hence, the resulting firm or industry productivity measures will be virtually useless.

In the United States the situation is particularly acute, with one or more agencies collecting value information and another entirely separate agency collecting price information. The various agencies have separate sampling frames and, at present, are not allowed even to exchange microinformation! To an outside impartial observer (i.e., to me), this situation cries out for reform. The various statistical agencies should be reorganized and combined into Statistics USA.

Statistics Canada, under the leadership of Phillip Smith, is instituting a new microdata management plan to manage the data burdens for large firms. Each large firm will have its own Statistics Canada representative, who will act as the single point of reference for all survey information to be collected from that firm. This will reduce respondent burden; but it will also ensure that the survey information is coherent, so that, for example, price information is matched up with the corresponding value information. It should also be mentioned that the national tax authority in Canada (Revenue Canada) has introduced a single business number for each firm in Canada; Statistics Canada will also use this number. I believe that every statistical agency should monitor the outcome of this experiment, and if it is successful, should plan to introduce a similar program. 
Many firms have taken advantage of the low cost of computing and have detailed data on all their financial transactions (e.g., they have the value of each sale and the quantity sold by commodity). This opens up the possibility of the statistical agency's replacing or supplementing their surveys on, say, prices of outputs, by firms' electronic submission to the statistical agency of their computerized transaction histories for a certain number of periods. This information would provide the industry or firm counterparts to the scanner data studies that have proved to be so useful in the context of the Consumer Price Index. This information would also lead to true microeconomic price and quantity indexes at the firm level and to accurate firm and industry productivity indexes.

I turn now to another topic that has not received the attention it deserves.

\subsection{System-Wide versus Sectoral Productivity Measurement}

Individual firms or establishments could be operating efficiently (i.e., could be on the frontiers of their production possibilities sets), yet the economy as a whole may not be operating efficiently. How can this be? The explanation for this phenomenon was given by Gerard Debreu $(1951)^{3}$ : there is a loss of system-wide output (or waste, to use Debreu's term) due to the imperfection of economic organization; that is, different production units, although technically efficient, face different prices for the same input or output, which causes net outputs aggregated across production units to fall below what is attainable if the economic system as a whole were efficient. In other words, a condition for system-wide efficiency is that all production units face the same price for each separate input or output that is produced by the economy as a whole. Thus, if producers face different prices for the same commodity and if production functions exhibit some substitutability, then producers will be induced to supply jointly an inefficient, economy-wide net output vector. What are sources of system-wide waste?

1. industry-specific taxes or subsidies that create differences in prices faced by production units for the same commodity; for example, an industry-specific subsidy for an output or a tax on the output of one indus-

3. Debreu $(1951,285)$ distinguished two other sources of waste in the allocation of resources: (1) waste due to the underemployment of available physical resources (e.g., unemployed workers), and (2) waste due to technical inefficiency in production. Obviously, the application of knowledge capital could be useful in diminishing waste (2). Waste (1) results from market imperfections between the aggregate production sector and the household sector of the economy. 
try where that output is used as an input by other industries (an example of the latter is a gasoline tax)

2. tariffs on imports or subsidies, or taxes on exports

3. union-induced wage differentials across firms for the same type of labor service

4. monopolistic or monopsonistic markups on commodities by firms, or any kind of price discrimination on the part of firms

5. imperfect regulation

6. a source of commodity price wedges related to imperfect regulation: the difficulty that multiproduct firms have in pricing their outputs, particularly when there are large fixed costs involved in producing new (or old) products (see Romer 1994)

Diewert and Fox $(1998,1999)$ further explore the problems of pricing new products, particularly when there is high inflation and the historical costaccounting techniques for pricing products break down.

On the problem of imperfect regulation, it is very difficult for government regulators to set "optimal" prices for the commodities that are regulated (recall my earlier discussion of the difficulties involved in determining what the appropriate prices for environmental "bads" should be). If the regulators are unable to determine the optimal prices for regulated commodities, the other producers that use the regulated outputs as inputs will generate system-wide waste. Examples of imperfect regulation might include marketing boards; telecommunications; airlines; environmental protection and health and safety regulations; regulation of labor markets, including the collective bargaining framework; regulation of the radiotelevision spectrum; and municipal zoning and building-code regulations. Another source of market imperfections between economic agents might be the legal system: Are property rights well defined and enforceable? If not, the resulting uncertainty prevents the market from assigning a definite value to the asset or resource under dispute and will generally prevent the asset from being utilized in its most profitable use.

A final source of price wedges between economic agents is the existence of widespread bribery and corruption. A bribe has roughly the same effect as an uncertain tax on a transaction, and will create distortion wedges between business units.

The main message I want to convey in this section is that even if an individual production unit is efficient, inefficient economic institutions, inappropriate government taxation policies, and monopolistic behavior on the part of firms or unions can create a system-wide loss of productive efficiency. Thus, in addition to the sources of productivity growth that are due to new knowledge and innovation and the diffusion of knowledge to the business units in the local marketplace, further sources of productivity gain can arise from the elimination of pricing wedges. 


\subsection{Additional Problems Statistical Agencies Face}

Statistical agencies face increasingly difficult problems in providing indexes of real output and input, which are the basic ingredients for computing productivity growth. ${ }^{4}$ The amount of resources devoted to research and the development of new products is probably greater than ever before. Moreover, improvements in communication mean that this new knowledge can diffuse into the local economy faster than ever before. Traditional index number theory assumes that the set of commodities being aggregated is constant and unchanging over time; thus, strictly speaking, traditional index number theory is not applicable in this New World of everincreasing choice sets. There is a lack of comparability of the set of commodities that exist in the current period with the set that existed in the previous period.

Most OECD economies are experiencing an increase in selfemployment and an increase in the formation of new business units. The entrance of new firms and the exit of old firms again create problems for productivity statistics: The traditional methodology assumes an unchanging set of business units. ${ }^{5}$ Thus, again, there is a lack of comparability: The set of firms and business units that exists in the present period is different from the set of firms that existed in the previous period.

When one examines the range of individual commodities produced by different firms in the same industry, one is struck by the tremendous amount of heterogeneity in the composition of these outputs. This heterogeneity makes comparisons of real output and productivity across firms somewhat dubious because their outputs may not be comparable.

Finally, the existence of seasonal commodities, on the lists of both inputs and outputs, again makes it difficult to compare this month's output or productivity with the previous month's. If a commodity produced this month was not produced at all in the previous month, between-month comparisons of output and productivity become meaningless. ${ }^{6}$

Thus, statistical agencies increasingly face the problem of a lack of comparability when they construct their estimates of business real output, input, and productivity. In addition, in sections 3.2-3.11, we saw that statistical agencies face many difficult conceptual measurement problems, in which reasonable statisticians could come up with quite different answers to these problems. These difficulties mean that it is increasingly difficult

4. Boskin (1997) also makes this point (and many other interesting points as well).

5. There is also the associated problem of firms' changing their product mix enough to shift them from one industry to another. This makes it difficult, if not impossible, to calculate accurate productivity growth rates for the two affected industries over the period when the switch takes place.

6 . For additional material on the difficulties that seasonal commodities create (particularly in high inflation situations), see Hill (1996) and Diewert (1998, 1999). 
for agencies to construct reproducible estimates of real output, input, and productivity. ${ }^{7}$ Unfortunately, I do not see any easy solution to these measurement problems on the horizon.

\section{References}

Boskin, M. J. 1997. Some thoughts on improving economic statistics to make them more relevant in the Information Age. Document prepared for the Joint Economic Committee, Office of the Vice Chairman, United States Congress, 22 October. Washington, D.C.: GPO.

Bureau of Labor Statistics (BLS). 1983. Trends in multifactor productivity, 1948-81. Bulletin 2178. Washington, D.C.: GPO.

Christensen, L. R., and D. W. Jorgenson. 1969. The measurement of U.S. real capital input, 1929-1967. Review of Income and Wealth ser. 15, no. 4 (December): 293-320.

1970. U.S. real product and real factor input, 1929-1967. Review of Income and Wealth ser. 16, no. 1 (March): 19-50.

Debreu, G. 1951. The coefficient of resource utilization. Econometrica 19:273-92.

Denison, E. F. 1985. Trends in American growth, 1929-1982. Washington, D.C.: Brookings Institution.

Diewert, W. E. 1980. Aggregation problems in the measurement of capital. In The measurement of capital, ed. Dan Usher, 433-528. Chicago: University of Chicago Press.

. 1998. High inflation, seasonal commodities and annual index numbers. Macroeconomic Dynamics 2:456-71.

- 1999. Index number approaches to seasonal adjustment. Macroeconomic Dynamics 3:48-68.

Diewert, W. E., and K. J. Fox. 1998. The productivity paradox and mismeasurement of economic activity. Paper presented at Eighth International Conference, Monetary Policy in a World of Knowledge-Based Growth, Quality Change, and Uncertain Measurement. 18 June, Institute for Monetary and Economic Studies, Bank of Japan, Tokyo.

1999. Can measurement error explain the productivity paradox? Canadian Journal of Economics 32:251-80.

Diewert, W. E., and A. M. Smith. 1994. Productivity measurement for a distribution firm. Journal of Productivity Analysis 5 (December): 335-47.

Hall, R. E., and D. W. Jorgenson. 1967. Tax policy and investment behavior. American Economic Review 57:391-414.

Harper, M. J., E. R. Berndt, and D. O. Wood. 1989. Rates of return and capital aggregation using alternative rental prices. In Technology and capital formation, ed. D. W. Jorgenson and R. Landau, 331-72. Cambridge: MIT Press.

Hausman, J. A. 1997. Valuation of new goods under perfect and imperfect competition. In The economics of new goods, ed. T. F. Bresnahan and R. J. Gordon, 209-37. Chicago: University of Chicago Press.

7. The reproducibility test for data construction states that every competent statistician would construct the same aggregate, given identical disaggregated information sets. The idea of this test dates back to the early accounting literature. 
1999. Cellular telephone, new products and the CPI. Journal of Business and Economic Statistics 17:1-7.

Hicks, J. R. 1940. The valuation of the social income. Economica 7:105-40.

1969. A theory of economic history. Oxford: Oxford University Press.

Hill, P. 1996. Inflation accounting: A manual on national accounting under conditions of high inflation. Paris: Organization for Economic Cooperation and Development.

1999. Tangibles, intangibles, and services: A new taxonomy for the classification of output. Canadian Journal of Economics 32:426-46.

Jorgenson, D. W., and B. M. Fraumeni. 1989. The accumulation of human and non-human capital, 1948-1984. In The measurement of saving, investment and wealth, ed. R. Lipsey and H. Tice, 227-82. Chicago: University of Chicago Press.

1992. Investment in education and U.S. economic growth. Scandinavian Journal of Economics 94 (supplement): 51-70.

Jorgenson, D. W., F. M. Gollop, and B. M. Fraumeni. 1987. Productivity and U.S. economic growth. Cambridge: Harvard University Press.

Jorgenson, D. W., and Z. Griliches. 1967. The explanation of productivity change. Review of Economic Studies 34:249-83.

Nordhaus, W. D., and E. D. Kokkelenberg. 1999. Nature's numbers: Expanding the national economic accounts to include the environment. Washington, D.C.: National Academy Press.

Organisation for Economic Cooperation and Development (OECD). 1993. Methods used by OECD countries to measure stocks of fixed capital, national accounts: Sources and methods, vol. 2. Paris: OECD.

Romer, P. 1994. New goods, old theory and the welfare costs of trade restrictions. Journal of Development Economics 43:5-38. 
